\title{
Planning of Plastic Surgery Practice to Say Sayonara
}

\author{
Lakshmi Saleem ${ }^{1}$ \\ ${ }^{1}$ Salaja Healthcare Pvt. Ltd., Hyderabad, India
}

Address for correspondence Lakshmi Saleem, 285 Merriweather Rd, Grossepointe Farms, MI 48236, United States (e-mail: lakshmi.saleem@gmail.com).

\begin{abstract}
Keywords

- plastic surgery

- retirement

- timing

Having seen the retired life of our professors both in general and plastic surgery and how lonely and isolated they were toward the end of their lives prompted me to discuss the retirement plans. The retirement from active surgical practice is indeed difficult and more so in plastic surgery. I feel that it needs meticulous planning for setting up a successful practice and when to say sayonara, just like treatment planning of any surgical procedure for perfect execution! At the end of M.Ch training, one should analyze oneself about the goal of the professional life and commit oneself to either a solo/ group practice as an independent institutional practice or in a corporate set-up or choose a state/central government set-up with some academic position. A successful plastic surgical practice is every plastic surgeon's dream and it comprises professional and financial successes with a sense of personal achievement. The factors involved in the selection of practice are family obligations-if parents or spouse are in medical profession with an existing establishment-individual talent, willingness to learn newer techniques, and acceptance of help from the other professional colleagues. At the same time, life needs to be balanced between the professional and family commitments without ignoring either of them with a deep social and community responsibility. But what is the correct time to say sayonara? The timing of retirement is difficult to get right, but the basic additional principle that guides one is "Primum non-nocere"-do no harm-to the receiver.
\end{abstract}

When is the correct time to bid "goodbye" to an active plastic surgical professional practice?

Not many suggest about setting up a successful plastic surgical practice, much less about how to retire!

I take the liberty of sharing retirement plans with my younger colleagues in some detail so that the budding plastic surgeons can modify factors to lead a fulfilling, healthier life without major regrets. Life is dynamic-"All is flux, and nothing stays still" (Heraclitus c.540-c.480 BCE). Every surgeon should consider adapting to the change occurring in one's personal and professional life as time goes. One must believe in oneself to succeed, leaving out the doubts which make us lose the very commitment to start.

Published online

November 20, 2020
DOI https://doi.org/

$10.1055 / \mathrm{s}-0040-1716431$ ISSN 0970-0358.
Retirement from active surgical practice is difficult, more so in plastic surgery. I feel that it needs meticulous planning just as is needed for any plastic surgery procedure. The further step is to execute perfectly-no textbook references or studies to fall back upon!

What prompted me to choose this topic?

After retiring at 70 years of age from a busy plastic surgery practice a year ago, time just flew by without a moment of boredom. I never missed the excitement of any surgical procedure so far. Setting a time frame to accept reality and sculpting myself accordingly helped me greatly.

Retirement should not be a forced process but a willing and planned decision. A successful practice in plastic surgery 
is every plastic surgeon's dream, may it be an institutional practice or an individual practice in the private sector or in a corporate set-up.

What comprises a successful practice?

I consider three aspects:

- Professional success.

- Financial success.

- A sense of personal achievement.

At the outset, plastic surgery practice in any place is particularly important to commit to either a solo/group practice or getting involved in a state/central government set-up with some academic position. Some of the factors that influence this are family commitments, individual talent, willingness to learn newer techniques, and to accept help for mutual growth.

The main features of plastic surgery practice are "profession and personality" and building a watertight compartment between these core areas is difficult! However, the outcome of one's career is interdependent on these two aspects. The "dreams and desires" of the surgeon directly influence the choices that one makes in the professional environment, and the attitude guides the direction of one's practices.

I would not hesitate to share my personal experience in the choices that I made along the professional path. My journey commenced in June 1978 with a M.Ch degree of plastic surgery from Post Graduate Institute of Medical Education and Research (PGIMER), Chandigarh. I was fortunate enough to get the extension as a registrar for 6 months, but I was not confident of my surgical skills. I opted to go to the United Kingdom to learn microvascular surgery and cosmetic surgery along with my husband, Saleem a general surgeon. I had the opportunity to be associated with the department of plastic surgery in Ulster Hospital and Royal Victoria Hospital in Belfast. Saleem could get into the general surgery easily but as a plastic surgeon, I could only get a locum post as and when vacancy appeared. I could learn a different approach for managing burns and trauma, and pick up tips of cosmetic surgery.

At the end of 5 years we had few options-settling in the United Kingdom; going to PGIMER Chandigarh as a faculty; work in the United Arab Emirates; or joining the state service of Andhra Pradesh. We opted to return to my hometown Vijayawada in 1984, for a solo surgical practice. Not having any plastic surgery facility in the area and with the simple motto of serving my own people, despite the suggestions of many to start practice in a bigger city like Hyderabad, prompted me to choose Vijayawada. I felt that my dreams were directing me toward my birthplace Vijayawada which is an important business center with a million population in the state of Andhra Pradesh. I was discouraged by many professional colleagues who feared that I may starve for plastic surgery work as there was not much of awareness. But thanks to my husband Saleem, a competent surgeon who gave a lot of physical and moral support in setting up and running the hospital and caring for our two young children and both our extended families.
One of the pearls of practice that I honored all through my practice is: when one works with passion and patience, perfection automatically follows. Professional satisfaction and financial gains have been the natural by-product.

Starting out, one must believe in oneself to succeed and get rid of the doubts. Doubts are like traitors to make us lose the belief to start. We become what we think about. "As we sow, so shall we reap."

A surgical career can run in four stages ${ }^{1}$ - phases of a career in plastic surgery can be ideated to four "life stages" of Dharma.

\section{Phase 1: Learning by Doing, Learning, and Doing-Brahmacharya (Student)}

A young plastic surgeon, immediately after qualifying, goes through the first stage of professional growth, comprising mostly 10 to 15 years. A lot of general plastic surgical work is required, and it would be essential to ameliorate all types of problems pertaining to reconstruction and add to the income. Having converted our house into a surgical facility with 10 beds, we were strictly following the general and plastic surgical work. I was treating all types of congenital deformities like clefts, hypospadias, and trauma including the acute burns. In this first phase of the practice, complications may be as per the volumes operated. Three important aspects that I concentrated to observe are the following:

- Transparency with the patient.

- Kindness with three times the TLC (tender loving care).

- Minimizing the patient's expenditure.

Availability to the needs of the patient, either in the preop visit or in follow-up, encourages a future referral. A satisfied patient generates another and is more powerful than any other marketing method, as everyone knows. Our stay in the same hospital campus helped us a great deal to satisfy all the patients round the clock. The work increased gradually and sooner than one expected, the number of plastic surgery patients increased day by day and a need for better facility was recognized.

We were able to build a hospital in 1988 of 30 beds with two operating rooms, including an isolated burns unit, and our residence on the top floor as our children and parents needed our attention. We were available for 24 hours a day and all the week. We were able to attend all the emergencies within minutes of arrival to the hospital.

\section{Phase 2: Work with Pleasure-Grihastha (House Holder)}

The second stage is a period of maturation and excellence occupying another 10 to 15 years. By then one would have identified the "core interests" and always be able to choose the surgical procedures of one's liking. Naturally, one would concentrate on one's interested subspecialty, learning from books, workshops, and conferences. It is advisable to be a student again, at least once a year to gain hands-on 
experience. The personal and professional lives continue to depend on each other in this phase as the professional life is more demanding with the growing family and aging parents!

We never had any difficulty in getting the patients for surgery and we always found a simple way of finding the solution for every problem with the available resources and the functional results were given priority rather than the aesthetics.

I started doing more of rhinoplasties and breast reductions as per the needs of the patients. At this stage, $51 \%$ of the surgical work was cosmetic. We used to have around 15 to 20 inpatients-a combination of burns, trauma, reconstructive, and cosmetic work.

Profession and family needed to be balanced without neglecting either of them. This is easier said than done and practically, one of these may appear as a burden. The individual with the right attitude will be able to "rope-walk" successfully balancing profession and family. Help from the spouse and other family members becomes valuable.

I started consultancy practice in Hyderabad once a week in a corporate hospital, with the idea of spending time with our teenage daughter who got admission into medical colleges in Hyderabad. I used to travel every week for 2 days for consultation and surgical work, while Saleem was taking care of the hospital in Vijayawada and looking after our son who was in high school. Travelling $300 \mathrm{~km}$ and surgical practice in two different cities were not easy and I had a simple way of avoiding burn-out by taking care of my diet, exercise, yoga, and adequate relaxation. But I had a lumbar disc prolapse which forced me for bed rest and to choose my clinical surgical work. I avoided acute major burns and reconstructive work and concentrated on cosmetic work. Most of the time the surgical work was helped by Saleem who was able to do all types of plastic surgical procedures on his own and we were mutually planning and supervising each other thus being able to continue the work even in cases needing long procedures.

\section{Phase 3: Working with Leisure-Vanaprastha (Preretirement)}

In this phase, the surgeon should choose a patient or a problem of one's own liking and concentrate on a few procedures that would not appear as a heavy work. Also endeavor to be almost an authority in that chosen work. A periodic self-objective medical examination becomes necessary in this phase of career. I needed to undergo surgery for my prolapsed disc and started my swimming classes to ease my back stiffness. It is here that one should also explore the option for retirement. By this time two more full-time plastic surgeons settled in Vijayawada. I made many efforts to get a full-time plastic surgeon to work with me sharing the practice but could not attract anyone. I reduced the workload in Vijayawada. In the meantime, our son got admission for PhD in London University having finished his Bachelors and Masters from Indian Institute of Technology, Mumbai. I opted to go to the United Kingdom for locum work at the age of 55 and be there for some time to recuperate from my back surgery and to help my son to settle down.

I was fortunate to work in one of the busiest units of plastic surgery at Selly Oak, Birmingham and Countess of Chester Hospital, Chester. In the latter, I worked with the breast surgeons and learnt practical tips of breast reductions to gain confidence. As I got the opportunity to teach voluntarily some students for fellowship examination in plastic surgery, I gained more clarity and understanding of the common procedures. After spending 2 years I returned home and chose to practice in Hyderabad full-time and worked for 2 days a week at Vijayawada, concentrating mostly on cosmetic surgery.

I made few good friends while working in the United Kingdom and they helped me in conducting free workshops for other plastic surgery colleagues to demonstrate the breast reductions, abdominoplasties, and liposuctions, and all the delegates benefitted from this exposure.

\section{Phase 4: Retirement for a Plastic Surgeon- Sannyasa (Renunciation)}

Very few would discuss this issue, mostly reluctant! What is the correct time to say "sayonara"? The timing of the retirement is exceedingly difficult to decide and I feel retirement planning may start from the day of qualifying as a plastic surgeon! It might sound strange, indeed. Loss of professional income, fear of change in personal life, loss of social status, and lifestyle planning outside surgery are the factors that come in the way. Surveys show that most of the surgeons retire around the age of 60 to 69 years. Financial stability is the most important key factor. Minimum saving of $10 \%$ from the earnings of the first day onwards may be sufficient for the retirement financial planning. Retirement should not be a forced process, but a willing and planned decision to be appreciable to both the patient population and our fraternity. It needs to consider the patients' safety, changing technology, and age-related physiological changes leading to physical awkwardness in the later decades of one's life, while deciding the timing of retirement. The basic additional principle that guides one is the principle of "Primum non-nocere"-do no harm! to the receiver. A reliable fellow specialist might provide a hint or two.

While looking for retirement options, the financial balance sheet of income and obligatory expenditure need to be considered as the trend of the patients' attitude is changing toward legal implications. Both partners may retire at the same time so that they can plan holidays and travel with ease. It is nice to reduce the working hours and take time out for visiting the places of one's interest with a prior scheduled plan of surgery for the patients. This helps to reduce the burn-out.

For the woman surgeon with more family obligations, the transition into retirement may be smooth and one may learn new things to move on in life. Trying to know oneself to understand what makes one happy-reading books, gardening, cooking, socializing, travelling, photography, music, 
sports, golf, yoga, meditation, the study of philosophy, law, or any such courses-may be some examples. One should understand the mission in life and devote time for the family or community. I wish to reiterate that if one has a preconceived idea of the above factors, one will have a satisfactory transition.

I started writing my autobiography with lot of commitment and passion to share with the younger generation how to balance work and life without ignoring any one aspect.

In the fourth phase of my career, I started "Salaja Trust" to do free plastic surgery camps, health check-ups, and screening of orphanages, government schools, and few adopted villages. I tried to impart some of my professional knowledge to the younger surgeons by conducting free workshops and free distribution of the mini textbook "Aesthetic Surgery for the Needy," which was written as a tribute to my late professor C. Balakrishnan.

The travel between the cities, long hours of surgery, and increased number of patients resulted in the second disc prolapse which prompted for surgical intervention to relieve the pain. I developed a rare skin malignancy which needed chemotherapy for 2 years. As per our planning with the required financial resources, we both took voluntary retirement and relocated to the United States to be with the family, and now live in Grosse Pointe Farms, Michigan.

Coming from the land of Sushruta I believe that yoga and meditation improve the quality of life. I practice and teach both.
"I shall be telling this with a sign, somewhere ages and ages hence: Two roads diverged in a wood, and I took the one less travelled, and that has made all the difference!"

- Robert Frost

"No one but ourselves save us and no one can, or no one may help us and we ourselves should walk the path alone."

- Buddha.

\section{Conclusion}

Having decided the type of the practice one wants to pursue after obtaining the qualification, keeping a 10 percent of income from the start as the retirement fund, and planning to fulfill the responsibilities with a time frame would guide a plastic surgeon in deciding the right time for retirement. Weaning the practice in the later part of the career and taking time off for travel and learning a new hobby may help to enjoy the retirement with the same excitement as starting the career!

\section{Conflict of Interest}

None.

\section{Reference}

1 Ranawat CS, Rothman RH. A surgeon's transition: when to retire from surgical practice. J Bone Joint Surg Am 2010; 92(8):e7 